\title{
Determinants of healthcare utilization and costs in COPD patients: first longitudinal results from the German COPD cohort COSYCONET
}

This article was published in the following Dove Press journal: International Journal of Chronic Obstructive Pulmonary Disease

\author{
Danalyn Byng, ${ }^{1,2, *}$ \\ Johanna I Lutter,',* \\ Margarethe E Wacker,' \\ Rudolf A Jörres, ${ }^{3}$ Xiaofei Liu, ${ }^{4}$ \\ Stefan Karrasch, ${ }^{3,5}$ \\ Holger Schulz, ${ }^{5}$ \\ Claus Vogelmeier, ${ }^{6}$ Rolf Holle' \\ On behalf of the \\ COSYCONET Consortium
}

'Institute of Health Economics and Health Care Management, Helmholtz Zentrum München,

GmbH - German Research Center for

Environmental Health, Comprehensive

Pneumology Center Munich (CPC-M), Member

of the German Center for Lung Research, 85764

Neuherberg, Germany; ${ }^{2}$ Institute for Medical

Informatics, Biometry and Epidemiology (IBE),

Ludwig-Maximilians-University Munich (LMU),

81377 Munich, Germany; ${ }^{3}$ Institute and

Outpatient Clinic for Occupational, Social and

Environmental Medicine, University Hospital,

LMU Munich, 80336 Munich, Germany; ${ }^{4}$ Institute

for Biostatistics, Hannover Medical School, 30625

Hannover, Germany; ${ }^{5}$ Institute of Epidemiology,

Helmholtz Zentrum München (GmbH) - German

Research Center for Environmental Health,

Comprehensive Pneumology Center Munich

(CPC-M), Member of the German Center for

Lung Research (DZL), 85764 Neuherberg,

Germany; ${ }^{6}$ Department of Respiratory Medicine,

University of Marburg, University Giessen and

Marburg Lung Center (UGMLC), Member of the

German Center for Lung Research, 35043

Marburg, Germany

*These authors contributed equally to this work

Correspondence: Johanna I Lutter Institute of Health Economics and Healthcare Management, Helmholtz

Zentrum München (GmbH) - German

Research Center for Environmental

Health, Ingolstädter Landstraße I, 85764

Neuherberg, Germany

Tel +49893। 87493 । 4

Email johanna.lutter@helmholtz-

muenchen.de
Background: In light of overall increasing healthcare expenditures, it is mandatory to study determinants of future costs in chronic diseases. This study reports the first longitudinal results on healthcare utilization and associated costs from the German chronic obstructive pulmonary disease (COPD) cohort COSYCONET.

Material and methods: Based on self-reported data of 1904 patients with COPD who attended the baseline and 18-month follow-up visits, direct costs were calculated for the 12 months preceding both examinations. Direct costs at follow-up were regressed on baseline disease severity and other co-variables to identify determinants of future costs. Change score models were developed to identify predictors of cost increases over 18 months. As possible predictors, models included GOLD grade, age, sex, education, smoking status, body mass index, comorbidity, years since COPD diagnosis, presence of symptoms, and exacerbation history.

Results: Inflation-adjusted mean annual direct costs increased by $5 \%$ (n.s., $€ 6,739$ to $€ 7,091)$ between the two visits. Annual future costs were significantly higher in baseline GOLD grades 2, 3, and 4 (factors 1.24, 95\%-confidence interval [1.07-1.43], 1.27 [1.09-1.48], 1.57 [1.27-1.93]). A history of moderate or severe exacerbations within 12 months, a comorbidity count $>3$, and the presence of dyspnea and underweight were significant predictors of cost increase (estimates ranging between $+€ 887$ and $+€ 3,679$, all $p<0.05)$.

Conclusions: Higher GOLD grade, comorbidity burden, dyspnea and moderate or severe exacerbations were determinants of elevated future costs and cost increases in COPD. In addition we identified underweight as independent risk factor for an increase in direct healthcare costs over time.

Keywords: direct costs, population-based, healthcare expenditures, outpatient costs, inpatient costs, change score

\section{Background}

Chronic obstructive pulmonary disease (COPD) is of major concern as a source of growing global burden of disease. ${ }^{1,2}$ Globally, its prevalence is estimated at 174.5 million individuals ${ }^{3}$ and expected to grow, in parallel with the aging of populations and the high frequency of smoking as the major risk factor. ${ }^{4}$

COPD is a progressive disease without effective cure, with symptoms and functional impairment closely linked to reductions in health-related quality of life (HRQoL), ${ }^{5,6}$ and high costs for healthcare systems. ${ }^{7}$ Opportunities to lower the costs of disease 
management point towards improving symptoms and reducing the frequency and severity of exacerbations that are known to be major drivers of disease progression and increased costs in COPD. ${ }^{8-10}$

The majority of available economic studies on healthcare utilization and costs in COPD are cross-sectional. ${ }^{7,11}$ For a disease that is progressive with huge variation between patients, longitudinal studies are of particular interest, as they may identify predictors of future developments. We have already performed a number of crosssectional analyses on direct and indirect costs in the large German COPD cohort COSYCONET, ${ }^{12}$ thereby providing a sound empirical basis for longitudinal analyses. In the present study we aimed to evaluate whether healthcare utilization and costs over a period of 18 months already allow for the identification of cost predictors from easily available baseline information, such as disease severity, demographic data and COPD-related symptoms and exacerbations. Since healthcare costs reflect HRQoL, predicting future direct costs and cost increases over 18 months could also identify risk groups who would benefit from improved treatment even within this relatively short period of time.

\section{Materials and methods}

\section{Study design and study cohort}

The German COPD cohort COSYCONET (German COPD and Systemic Consequences - Comorbidities Network) is a prospective, observational, multicenter cohort study. ${ }^{13}$ A total of 2,741 subjects were recruited in 31 study centers across Germany between September 2010 and December 2013. After the baseline visit, participants were evaluated in follow-up visits at 6 and 18 months, and further ongoing visits. Data for the present analysis were drawn from the baseline examination (visit 1) and the 18-month follow-up (visit 3). Patients fulfilling enrolment inclusion criteria into the cohort were aged 40 years and older with a physician diagnosis of COPD (according to the GOLD criteria) or chronic bronchitis. Additionally, patients must have had availability for repeated study visits over at least 18 months. Patients were excluded if they experienced any of the following: having undergone major lung surgery (eg, lung volume reduction, lung transplant); moderate or severe exacerbation within the last four weeks; having a lung tumor; physical or cognitive impairment resulting in an inability to walk or understand the intention of the project.

\section{Healthcare utilization and cost measurement}

Health insurance coverage in Germany is compulsory. Statutory German health insurance scheme based on income-oriented contributions cover $89 \%$ of the German population, whereas the remaining $11 \%$ receive coverage through a private health insurance scheme based on riskoriented contributions. Under both schemes, the majority of health services are covered. Exceptions are co-payments for drugs and inpatient hospital days ( $€ 10$ per outpatient prescription and $€ 10$ per inpatient hospital day), which likely minimally financially burden patients with COPD.

All-cause healthcare utilization was assessed from standardized interviews and questionnaires at baseline and after 18 months. The reason for accessing care was not specified, while different time frames for each type of care were used in order to minimize recall bias. ${ }^{14}$ Outpatient care was defined by the number of outpatient physician visits in the previous three months. Inpatient care was captured as the number of hospital days in the previous 12 months. Medication use was assessed according to the number of prescription pharmaceuticals used in the previous week, based on defined daily doses and patient-reported information on drug code. ${ }^{15}$

In order to estimate the costs for the preceding year, outpatient physician visits and prescribed medication use were extrapolated to a 12 -month period. In- and outpatient visits were multiplied by the corresponding 2012 German unit costs, ${ }^{16}$ and medication costs per year were calculated from 2012 pharmacy retail prices. ${ }^{17}$ The standardized unit costs derived from Bock et al's 2012 study $^{16}$ are based on a societal perspective and allow the comparison of healthcare utilization across Germany, regardless of location. There was no indication of clustering effects by geographic region and study center, and these factors are therefore not controlled for in this analysis.

\section{Covariates: participant characteristics, disease status, lung function, symptoms, comorbidities, and quality of life}

This study emphasizes four major characteristics of the disease: severity of airflow obstruction, presence of symptoms, exacerbation history/risk, and presence of 
comorbidities. As further characteristics we included age, sex, highest attained level of school education, smoking status, body mass index (BMI, $\mathrm{kg} / \mathrm{m}^{2}$ ), and years since COPD diagnosis. Indices of HRQoL at baseline (Saint George's Respiratory Questionnaire [SGRQ] and COPD Assessment Test [CAT]) were used to compare participants lost to follow-up with those included in the present analysis. The SGRQ is a HRQoL variable measuring symptoms, functional impairment, and psycho-social impact. $^{18}$

\section{Lung function and COPD definition}

COPD was defined according to the spirometric Global Initiative for Chronic Obstructive Lung Disease (GOLD) criteria, requiring a ratio $\mathrm{FEV}_{1} / \mathrm{FVC}$ below $70 \%{ }^{9}$ as obtained in standardized post-bronchodilator spirometry. Based on the results, participants were assigned GOLD grades 1 to 4 according to $\mathrm{FEV}_{1}$ values as percent predicted according to the Global Lung Function Initiative. ${ }^{19}$ A total of 301 participants had $\mathrm{FEV}_{1} / \mathrm{FVC} \geq 0.7$ at baseline, despite reporting a diagnosis of COPD by a physician. These participants were included in this analysis as "grade unclassified", since they are patients receiving treatment for COPD within the healthcare system. Patients identified as having alpha 1-antitrypsin deficiency (A1ATD, n=170 at baseline), either through self-reports or according to their use of A1ATD substitution therapy, were excluded from the present analysis due to the known high costs of A1ATD substitution therapy, which may bias cost estimates. Cost and utilization data of this subgroup are reported elsewhere. ${ }^{20}$

\section{Symptoms, exacerbation history, and comorbidities}

Three binary variables were constructed from scores on selfassessed symptom severity and functional impairment questionnaires, indicating the presence of three important COPD-related symptoms: cough, sputum production, and dyspnea. Cough and sputum production variables were taken from responses to the $\mathrm{CAT}^{21}$ The symptom-related questions in the CAT utilize a scale of 0 to 5 , with higher scores representing greater symptoms or impairment. The presence of cough was defined by a cut-off of $>2$ for responses to the question "I never cough/I cough all the time". A similar variable was defined for the presence of sputum production, with a cut-off of $>2$ in response to "I have no phlegm (mucus) in my chest at all/My chest is completely full of phlegm (mucus)". A variable representing dyspnea was adapted from responses on the British modified Medical Research Council (mMRC) Questionnaire, ${ }^{22}$ which utilizes a scale of 0 to 4 , with higher grades indicating more severe breathlessness. A cut-off of $\geq 2$ was chosen for this variable to define groups with less/more breathlessness. Exacerbation history was captured using mutually exclusive categories ranked by severity (no exacerbation to severe exacerbation) during the 12 months preceding the examination. The different severity levels of exacerbations were defined according to GOLD (acute respiratory worsening for several days and the need for specific measures, mild: handled by the patient itself, moderate: visited their primary care physician, severe: led to a hospital admission).

The presence of 33 pre-defined comorbidities was assessed through the following question, "Has a physician ever diagnosed you with one of the following diseases?" This information was consolidated into one variable representing comorbidity count, which has been shown to be useful in quantifying comorbidity among COPD populations. $^{23}$ The regression models included a binary version of this variable, using the median value as the cutoff ( $>3$ comorbidities at baseline) to define groups with low/ high comorbidity burden. This was also done in accordance with previously published COSYCONET data. ${ }^{6,24}$

\section{Statistical analyses}

To quantify the changes in patient characteristics, healthcare utilization and costs between the two visits, descriptive analyses and statistical tests for paired data were used, specifically the McNemar test for categorical variables, and the Wilcoxon Signed Rank test for numeric variables.

The association of baseline characteristics with future costs and with cost increases, both after 18 months of follow-up, were analyzed using gamma regression and change score models, respectively. To prevent the influence of extreme cost outliers on the results of the regression models, cost data were winsorized at the $95 \%$ level. All regression models included the baseline variables GOLD grade, age, sex, education, smoking status, BMI, comorbidity count, years since COPD diagnosis, presence of symptoms (cough, sputum production, dyspnea), and exacerbation history in the previous 12 months.

First, the association of baseline COPD grades and other covariates with annual costs measured at the 18month follow-up were estimated via generalized linear regression models (GLM) with separate models for outpatient, inpatient, medication, other (physiotherapy and 
rehabilitation), and total annual direct costs. Given the highly skewed distribution of cost data, we used a GLM approach with a log-link function and gamma distribution. The exponentials of the regression coefficients can be interpreted as factors.

In a second step, change score models were used to explore the baseline determinants of direct cost changes within 18 months. Differences between costs measured at follow-up and baseline were calculated based on the winsorized data set. Calculated cost changes were then regressed on baseline characteristics using GLM models with normal distribution. Positive values can be interpreted as an increase in costs, whereas negative values refer to a reduction of costs from baseline to follow-up. In addition to the above named covariates, direct costs at baseline were considered as a potential predictor of cost changes in the change score models.

A significant proportion of participants from the baseline study cohort $(667 / 2741,24 \%)$ were lost to follow-up at 18 months due to various reasons, and were thus excluded from the main analyses. Descriptive analyses were therefore undertaken to compare the baseline characteristics of participants present at baseline and 18 months, and those lost to follow-up. For this purpose, independent samples $t$-tests for continuous variables, $\mathrm{Chi}^{2}$-tests for categorical variables, and Mann-Whitney $U$ tests for non-normally distributed continuous variables were applied.

All analyses were performed using the SAS software (SAS Institute Inc., Cary, NC, USA, Version 9.3) package. $P$-values of 0.05 or less were considered statistically significant.

\section{Sensitivity analyses}

A sensitivity analysis was performed to account for dropout bias by implementing Inverse Probability Weighting (IPW) in the regression analyses. Weights were calculated for the complete cases based on the inverse probability of attending the follow-up assessment. This was modelled using demographic variables, disease characteristics and quality of life, all measured at baseline. Complete cases that were found to be similar to patients who dropped out, were assigned higher weights resulting in a weighted population imitating the cohort as recruited at baseline. Patients who died between baseline and follow-up were excluded from the IPW calculation. The sensitivity analysis was performed for the outcome total direct costs and both models: the gamma regression model and the change score model.
Additionally, all models were calculated with the nonwinsorized cost data to ensure the replicability of the results based on the raw data.

\section{Ethics statement}

The COSYCONET study was approved by the Ethics Committees of the local study centers. This approval covered the subsequent data analyses as performed here. All participants gave their written informed consent.

\section{Results}

\section{Study population}

After excluding 667 participants without data for the 18month follow-up visit and another 170 participants with A1ATD, data from a total of 1904 participants were available for the analyses of baseline and 18 month follow-up data (Table 1). The comparison between the two time points showed a statistically significant decrease in lung function, as demonstrated by an overall fall in $\mathrm{FEV}_{1}$ $(1.72 \mathrm{~L}$ vs $1.64 \mathrm{~L}, p<0.0001)$. This was accompanied by an increase in the proportion of underweight patients (2.6 vs $3.4 \%, p=0.0053$ ), as well as those reporting the presence of dyspnea ( 41.3 vs $43.5 \%, p=0.0268$ ). The mean comorbidity count was also significantly higher at the 18month follow-up (3.9 vs 4.7, $p<0.0001)$. In contrast, at the follow-up a lower proportion of patients reported a severe exacerbation in the previous 12 months (17.6 vs $12.9 \%$, $p<0.0001)$.

\section{Healthcare utilization}

Healthcare utilization is reported in Table 2. Among the 1904 patients, the proportion of users of outpatient care (general practitioner, specialist, and hospital) decreased (95.7 vs $92.9 \%, p<0.0001$ ), as did the mean total number of visits (6.3 vs 5.8, $p<0.0001)$, while there were no significant changes in inpatient hospital care during this time period. The proportion of participants using prescribed medication was high at both visits, with an increase in the mean number of prescribed medicines (5.7 vs 6.0, $p<0.0001)$; this increase was consistent across all GOLD grades (Table 2).

\section{Costs}

\section{Comparison of costs at baseline and follow-up}

Mean annual direct costs per person are shown in Table 2. Consistent with changes observed in outpatient services utilization, mean outpatient costs slightly dropped over 


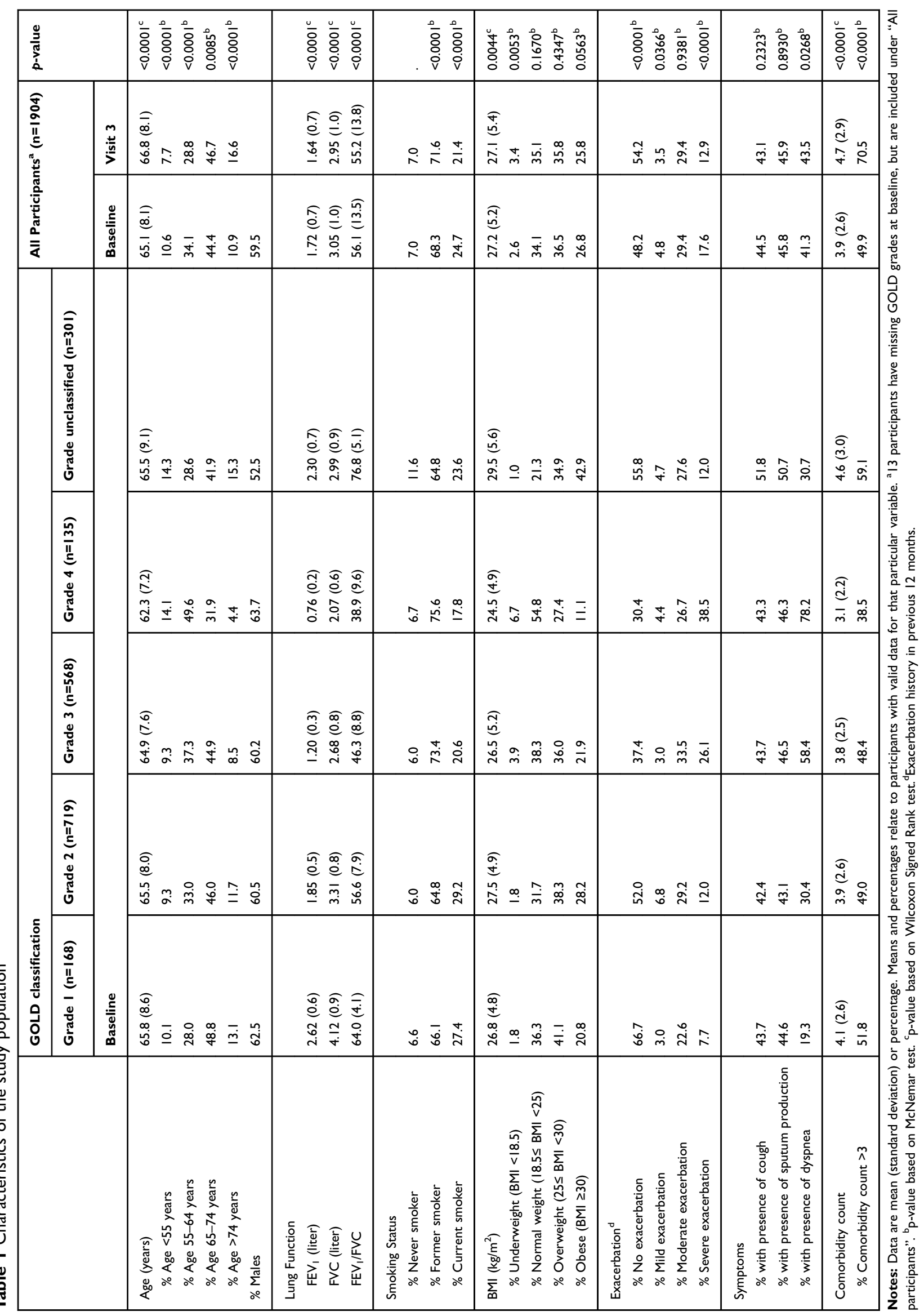




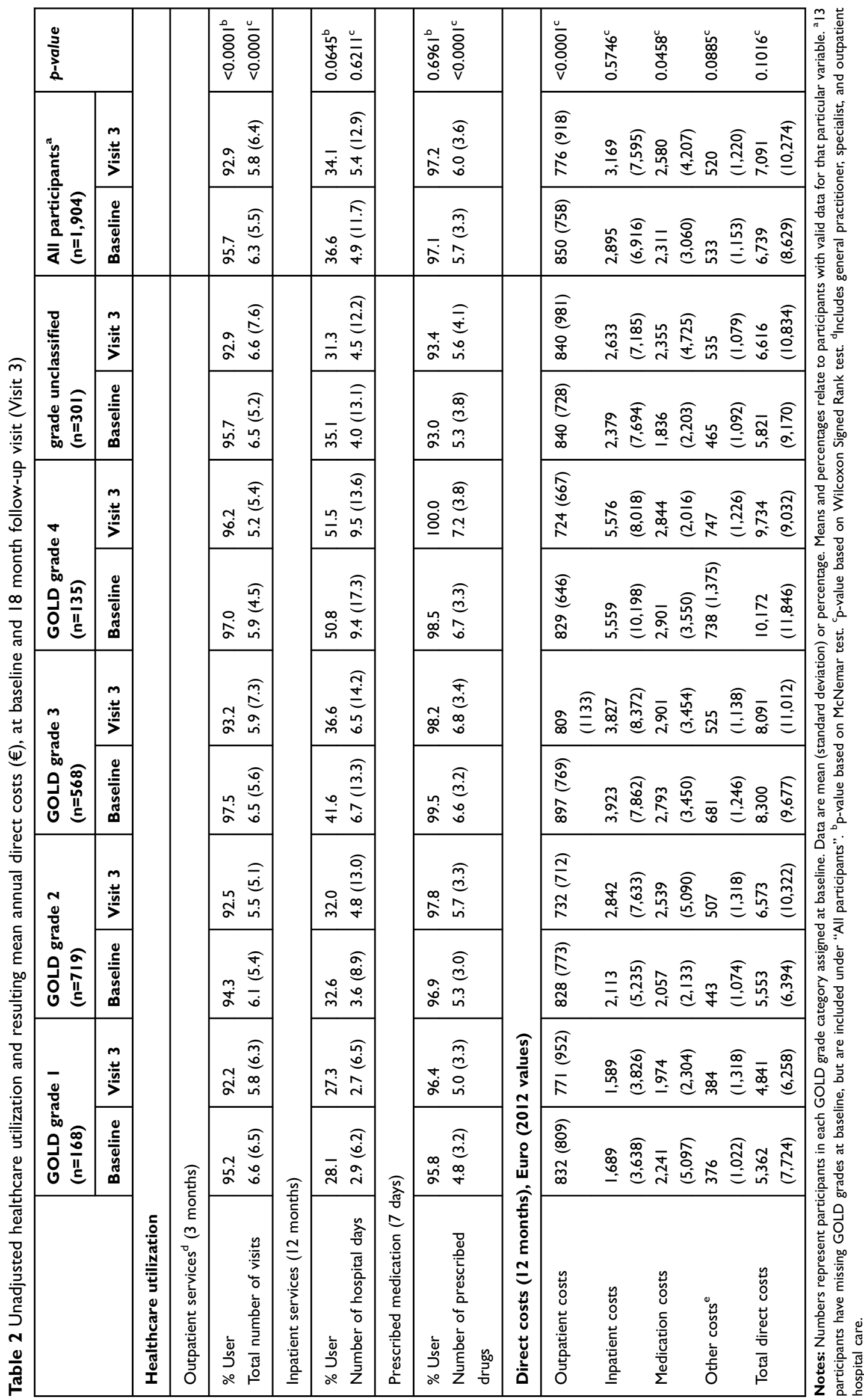


18 months, whereas costs for inpatient services and medication utilization increased, however statistically significantly only for medication. Inpatient costs, followed by medication costs constituted the largest proportions of total direct costs at both time points. Total annual direct costs also showed a $5.2 \%$ increase (€6,739 vs $€ 7,091$ per patient), though this was not statistically significant due to large interindividual variation.

\section{Determinants of future annual costs}

Table 3 displays the results of the regression analysis for future annual costs. The factors for COPD grades 2 to 4 relative to grade 1 (reference) ranged from 1.24 to 1.57. Higher education was associated with lower costs (OR 0.90; 95\% CI 0.80-1.00). The key drivers of future annual costs were underweight (OR $1.65 ; 95 \%$ CI 1.28-2.13) and the occurrence of a severe exacerbation in the 12 months before baseline (OR 1.73; 95\%CI 1.55-1.93). Other variables with a significant impact on future annual costs included age 65-74 years (OR 1.24; 95\%CI $1.07-1.42$ ), age $>74$ years (OR 1.20; 95\%CI 1.01-1.43), being a current smoker (OR 1.19; 95\%CI 1.00-1.42), comorbidity count $>3$ (OR 1.49; 95\%CI 1.37-1.61), presence of dyspnea (OR 1.30; 95\%CI 1.19-1.41), and moderate exacerbation in the 12 months before baseline (OR 1.22; 95\%CI 1.11-1.34). The majority of associations for inpatient and medication costs were similar to those for the total costs, whereas few variables were associated with future outpatient and other costs (see Table 3 ).

\section{Predictors of cost increases over 18 months of follow-up}

Table 4 shows the results of the five change score models, describing the predictive value for baseline variables on the increases in annual direct costs at follow-up. COPD grade 4 was significantly associated with increases in total annual costs $(€ 2,346 ; 95 \% \mathrm{CI} € 960-€ 3,732)$, as was age 65-74 years $(€ 1,018$; 95\%CI: $€ 66-€ 1,969)$, a history of moderate (€887; 95\%CI: $€ 258-€ 1,516)$ or severe $(€ 1,425 ; \quad 95 \% \mathrm{CI} \quad € 577-€ 2,273) \quad$ exacerbations, a comorbidity count of $>3(€ 1,579 ; 95 \% \mathrm{CI} € 1,029-€$ $2,129)$, and the presence of dyspnea $(€ 1,131 ; 95 \% \mathrm{CI}$ $€ 538-€ 1,724)$. Being underweight also contributed to an increase in total direct costs at follow-up $(€ 3,679,95 \% \mathrm{CI}$ $€ 1,978-€ 5,380)$. Baseline costs, which were included to account for a possible regression to the mean effect, were highly significant for all cost categories. Sex, smoking status, years since diagnosis and symptoms (excluding dyspnea) did not have a statistically significant impact on the increases in total direct costs at the 18-month follow-up visit.

\section{Sensitivity analyses}

The models including the inverse probability weights identified similar determinants for future costs and cost increases compared to the complete case analysis. However, in comparison with the estimates derived from the complete case analysis (Table 4), the IPW estimated larger cost increases, ranging from $+€ 38$ (GOLD grade 4) to $+€ 326$ (underweight), indicating an underestimation of cost increases, when excluding participants lost to follow-up. The effect estimates of the Gamma regression model remained nearly unchanged (See Table 6).

When analyzing the association of baseline patient characteristics with future total direct costs (GLM model) based on the non-winsorized cost data set, the category "COPD grade unclassified" also reached statistical significance, with 1.26 times higher future costs compared to grade 1. No further changes in terms of statistical significance or direction of estimates were observed, although due to the broader distribution of cost data, all confidence intervals were considerably wider. Moreover, applying the change score model to the non-winsorized annual total direct costs had a limited impact on the results. Whereas COPD grade 4 and exacerbation history were no longer significantly associated with an increase in costs, estimates for underweight, comorbidity burden and dyspnea remained unchanged and were still predictors of annual direct cost increases.

\section{Participants lost to follow-up}

The comparison of baseline data between participants present for both visits with those of patients lost to follow-up indicated significant differences between the groups (Table 5). On average, participants lost to follow-up were older, had poorer lung function, experienced at least one severe exacerbation, reported the presence of symptoms and had worse HRQoL at baseline. There were also obvious differences regarding utilization and costs, whereby patients lost to follow-up showed significantly higher direct costs at baseline.

\section{Discussion}

In this study, we analyzed longitudinal data on the utilization of healthcare services and associated costs among COPD patients, and identified determinants of future annual direct costs and increases. On average, there was 


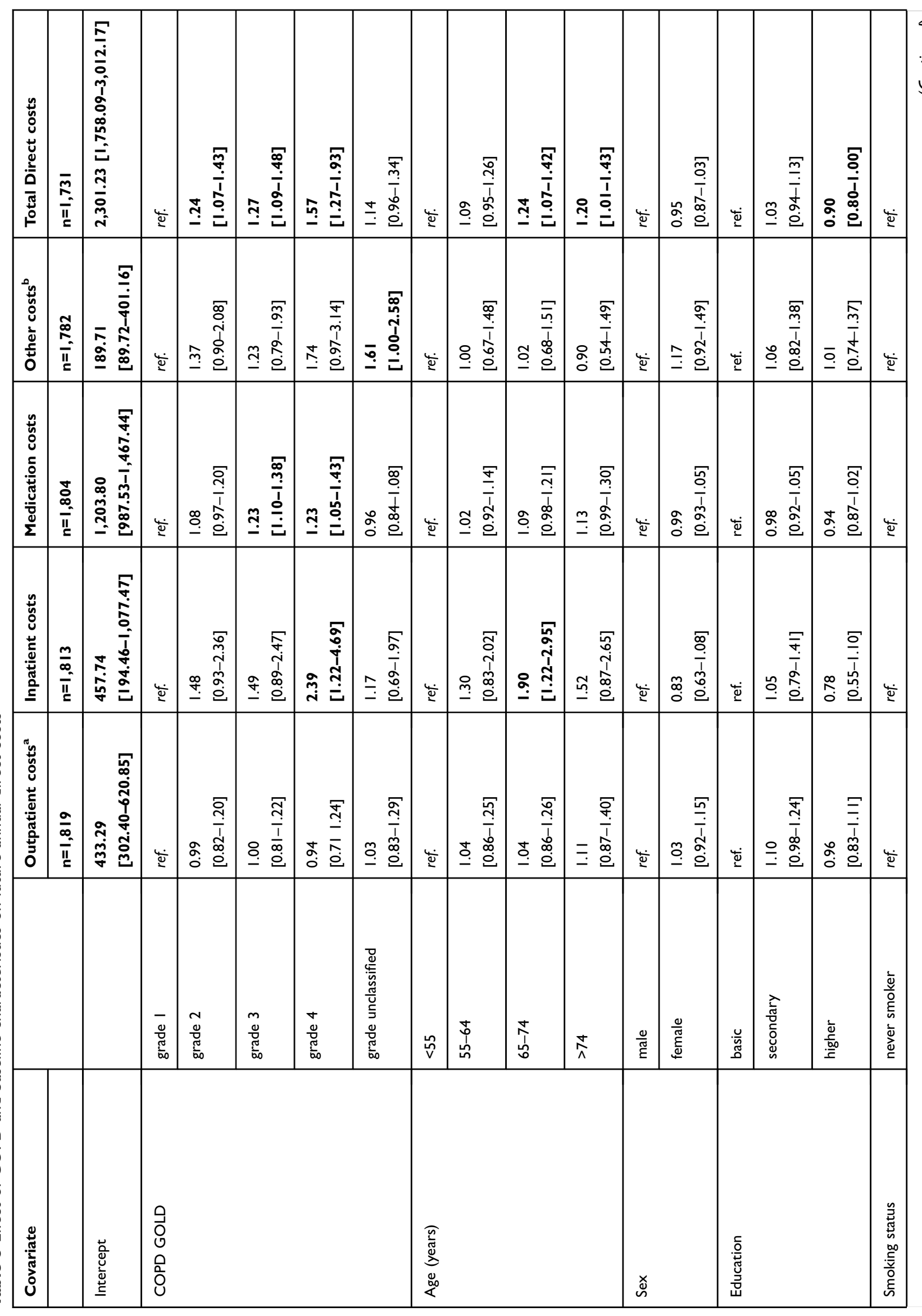




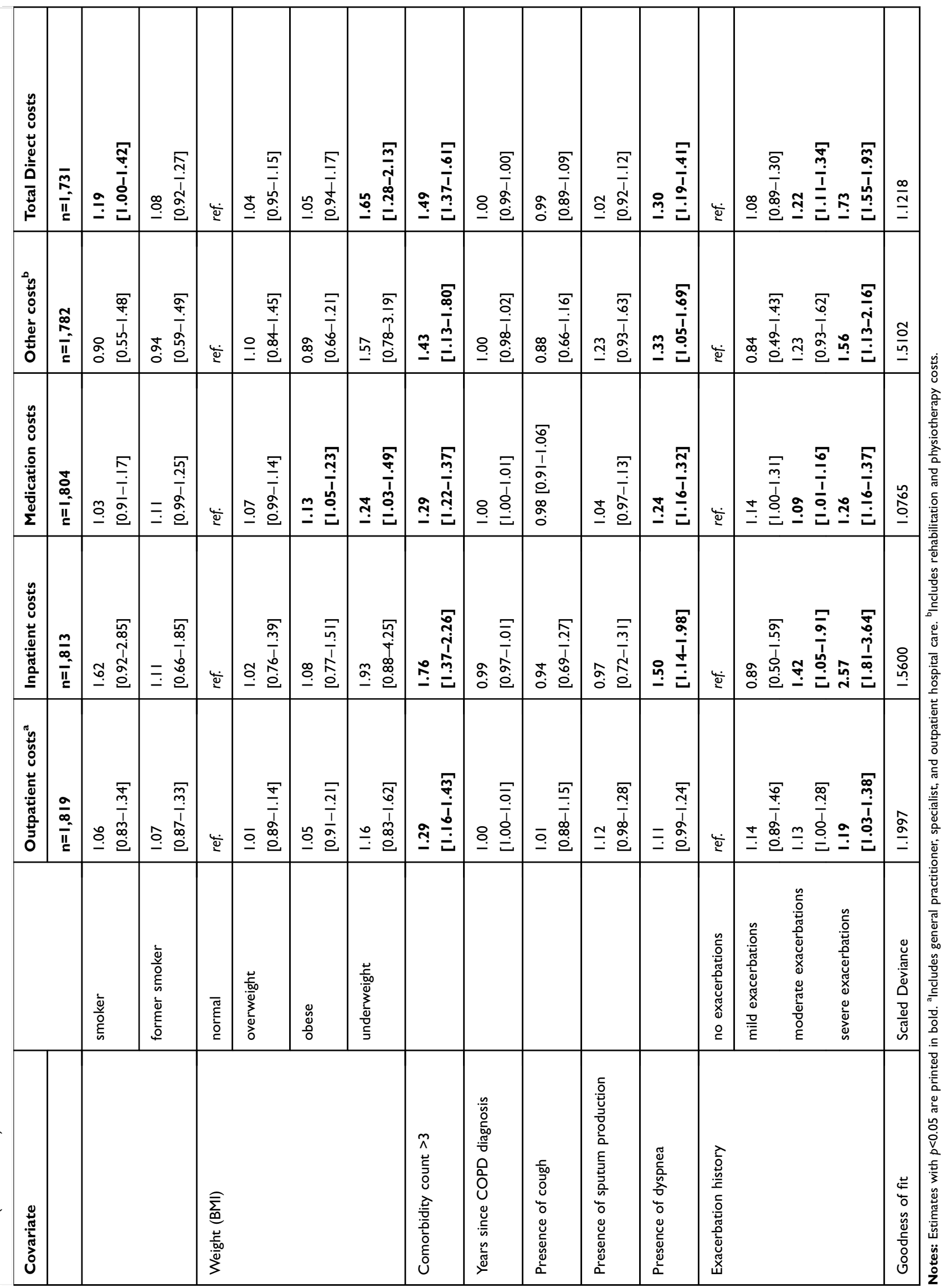




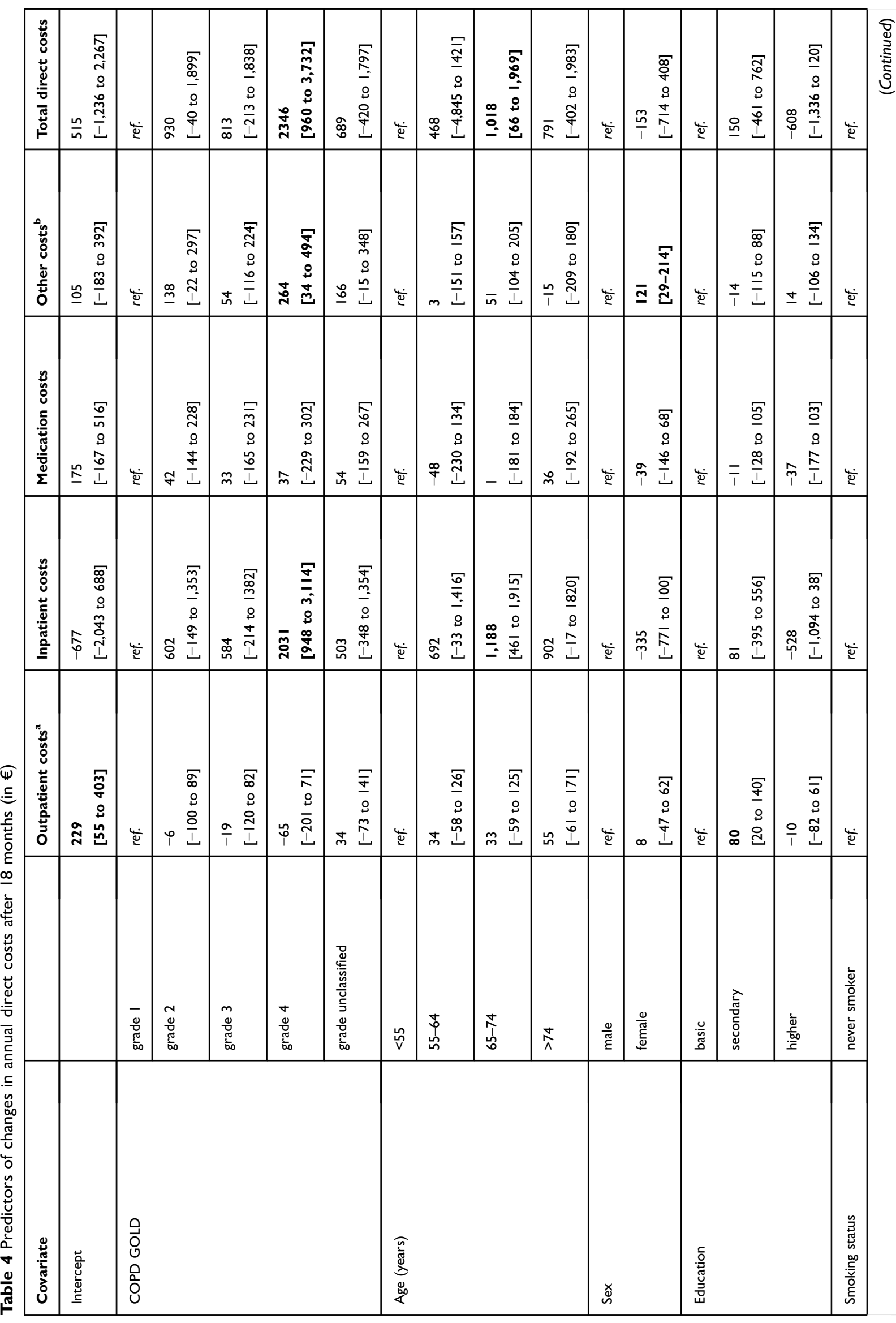




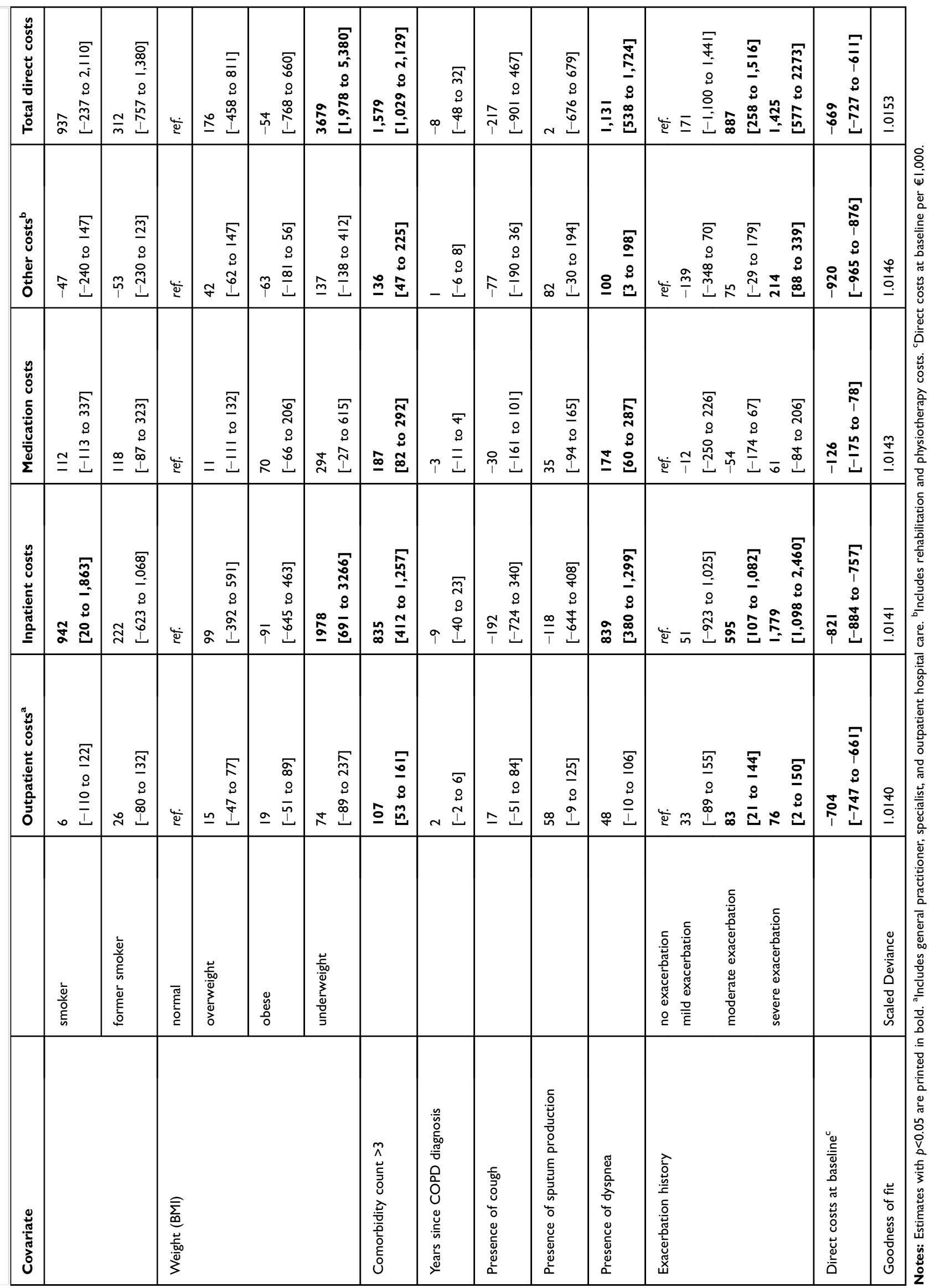


Table 5 Baseline comparison of demographics and disease status, patients present for both visits (study participants) vs patients lost to follow-up (baseline only)

\begin{tabular}{|c|c|c|c|}
\hline & $\begin{array}{l}\text { Study participants with } \\
\text { follow-up } \\
(n=1904)\end{array}$ & $\begin{array}{l}\text { Baseline only } \\
(n=667)\end{array}$ & p-value \\
\hline$\%$ grade unclassified & 15.9 & I7.I & $<0.000 \mathrm{I}^{\mathrm{a}}$ \\
\hline \% GOLD grade I & 8.9 & 4.4 & \\
\hline$\%$ GOLD grade 2 & 38.0 & 28.5 & \\
\hline \% GOLD grade 3 & 30.0 & 36.4 & \\
\hline \% GOLD grade 4 & 7.1 & 13.5 & \\
\hline Age (years) & $65.1(8.1)$ & $66.0(9.2)$ & $0.0262^{\mathrm{b}}$ \\
\hline$\%$ Males & 59.5 & 58.9 & $0.8094^{a}$ \\
\hline$\%$ Basic school education & 55.7 & 59.1 & $0.1492^{\mathrm{a}}$ \\
\hline \% Secondary school education & 27.2 & 23.4 & \\
\hline \% Higher school education & 17.1 & 17.5 & \\
\hline $\mathrm{FEV}_{1} / \mathrm{FVC}$ & $56.1(13.5)$ & $54.5(14.5)$ & $0.0130^{\mathrm{b}}$ \\
\hline \% Never smoker & 7.0 & 6.0 & $0.0818^{\mathrm{a}}$ \\
\hline$\%$ Former smoker & 68.3 & 65.1 & \\
\hline$\%$ Current smoker & 24.7 & 28.9 & \\
\hline BMI $\left(\mathrm{kg} / \mathrm{m}^{2}\right)$ & $27.2(5.2)$ & $27.1(6.0)$ & $0.5464^{\mathrm{b}}$ \\
\hline \% Underweight $(\mathrm{BMI}<\mid 8.5)$ & 2.6 & 5.1 & $0.0198^{\mathrm{a}}$ \\
\hline$\%$ Normal weight $(18.5 \leq \mathrm{BMI}<25)$ & 34.1 & 33.4 & \\
\hline$\%$ Overweight $(25 \leq \mathrm{BMI}<30)$ & 36.5 & 36.4 & \\
\hline$\%$ Obese $(\mathrm{BMI} \geq 30)$ & 26.8 & 25.0 & \\
\hline \% No exacerbation & 48.2 & 42.7 & $0.0012^{\mathrm{a}}$ \\
\hline$\%$ Mild exacerbation & 4.8 & 5.4 & \\
\hline \% Moderate exacerbation & 29.4 & 27.5 & \\
\hline \% Severe exacerbation & 17.6 & 24.4 & \\
\hline$\%$ with presence of cough & 44.5 & 50.6 & $0.0065^{\mathrm{a}}$ \\
\hline$\%$ with presence of sputum production & 45.8 & 51.4 & $0.0137^{\mathrm{a}}$ \\
\hline$\%$ with presence of dyspnea & 41.2 & 59.3 & $<0.0001^{\mathrm{a}}$ \\
\hline Number of comorbidities & $3.9(2.6)$ & $3.8(2.8)$ & $0.3424^{c}$ \\
\hline$S_{G R Q}$ & $40.7(19.4)$ & $48.3(21.1)$ & $0.0001^{b}$ \\
\hline Total direct costs ${ }^{\mathrm{e}}$ & $6,739(8,628)$ & $8,657(12,789)$ & 0.0002 \\
\hline
\end{tabular}

Notes: Data are mean (standard deviation) or percentage. Means and percentages relate to participants with valid data for that particular variable. ${ }^{a} \mathrm{p}$-value based on Chi ${ }^{2}$ test. ${ }^{\mathrm{b}} \mathrm{p}$-value based on $t$-test. ${ }^{\mathrm{c}} \mathrm{p}$-value based on Mann-Whitney $\mathrm{U}$ test. ${ }^{\mathrm{d}}$ Scoring ranges from 0 to 100 , with higher scores indicating worse HRQoL. $\mathrm{e}$ Includes rehabilitation and physiotherapy costs, in addition to outpatient, inpatient and medication costs.

a non-significant 5\% increase in direct costs over a period of 18 months. Statistically significant baseline determinants of increases in costs included a history of moderate or severe exacerbations in the previous 12 months, a comorbidity count $>3$, being underweight, and the presence of dyspnea.

Of the small number of published longitudinal studies on costs and utilization in COPD, few have reported developments of costs over time from a cohort perspective. For example, a claims database study by Jansson et al followed a relatively small sample of patients with COPD $(n=244)$ for more than 10 years, and compared the costs in 1999 with those in 2010. However, the authors did neither report an overall change in costs for the total sample nor did they identify baseline characteristics associated with individual cost changes. ${ }^{25}$ Medication has consistently been identified as one of the most important contributors to direct costs in COPD. ${ }^{12,26,27}$ Our study confirms the role of medication by the observed $11.6 \%$ increase in unadjusted all-cause medication costs even after just 18 months. These increases were seen in GOLD grades 2 and 3 and in physician diagnosed COPD patients without airflow obstruction at visit 1 (GOLD unclassified). 
Table 6 Determinants of future costs and cost increases calculated with Inverse Probability Weighting to adjust for dropout bias

\begin{tabular}{|c|c|c|c|}
\hline & & $\begin{array}{l}\text { Future costs (Table 3) - Gamma regres- } \\
\text { sion model }\end{array}$ & $\begin{array}{l}\text { Cost increases (Table 4) - Change } \\
\text { Score model }\end{array}$ \\
\hline & & Total Direct costs & Total Direct costs \\
\hline Intercept & & $2,400[1,829$ to 3,150$]$ & $660[-1,|3|$ to $2,45 \mid]$ \\
\hline \multirow[t]{5}{*}{ COPD GOLD } & grade I & ref. & ref. \\
\hline & grade 2 & $1.23[1.05$ to 1.43$]$ & $923[-116$ to 1,961$]$ \\
\hline & grade 3 & $1.25[1.07$ to 1.47$]$ & $788[-298$ to 1,873$]$ \\
\hline & grade 4 & 1.57 [1.28 to 1.93$]$ & $2,384[986$ to $3,78 I]$ \\
\hline & grade unclassified & 1.13 [0.95 to 1.34$]$ & $753[-409$ to $1,9 \mid 4]$ \\
\hline \multirow[t]{4}{*}{ Age (years) } & $<55$ & ref. & ref. \\
\hline & $55-64$ & 1.08 [0.94 to I.24] & $424[-522$ to 1,370$]$ \\
\hline & $65-74$ & $1.22[1.06$ to 1.40$]$ & $929[-14$ to 1,873$]$ \\
\hline & $>74$ & 1.16 [0.98 to 1.38$]$ & $621[-545$ to 1,786$]$ \\
\hline \multirow[t]{2}{*}{ Sex } & male & ref. & ref. \\
\hline & female & 0.95 [0.87 to 1.03$]$ & $-16 \mid$ [ -728 to 407$]$ \\
\hline \multirow[t]{3}{*}{ Education } & basic & ref. & ref. \\
\hline & secondary & $1.03[0.94$ to 1.13$]$ & 147 [-478 to 772$]$ \\
\hline & higher & $0.89[0.80$ to 0.99$]$ & $-638[-1,373$ to 96$]$ \\
\hline \multirow[t]{3}{*}{ Smoking status } & never smoker & ref. & ref. \\
\hline & smoker & 1.17 [0.98 to 1.39$]$ & $810[-374$ to 1,993$]$ \\
\hline & former smoker & 1.08 [0.92 to 1.26$]$ & $283[-799$ to 1,365$]$ \\
\hline \multirow[t]{4}{*}{ Weight (BMI) } & normal & ref. & ref. \\
\hline & overweight & $1.05[0.95$ to 1.15$]$ & $237[-408$ to $88 I]$ \\
\hline & obese & $1.05[0.94$ to 1.17$]$ & $-35[-762$ to 692$]$ \\
\hline & underweight & $1.69[1.33$ to 2.15$]$ & $4005[2,365$ to 5,645$]$ \\
\hline Comorbidity count $>3$ & & $1.48[1.36$ to 1.60$]$ & $\mid 589[|, 03|$ to $2, \mid 47]$ \\
\hline $\begin{array}{l}\text { Years since COPD } \\
\text { diagnosis }\end{array}$ & & $1.00[0.99$ to 1.00$]$ & $-7[-48$ to 34$]$ \\
\hline Presence of cough & & 0.98 [0.89 to 1.09$]$ & $-290[-984$ to 403$]$ \\
\hline $\begin{array}{l}\text { Presence of sputum } \\
\text { production }\end{array}$ & & $1.02[0.92$ to 1.12$]$ & 39 [-648 to 726$]$ \\
\hline Presence of dyspnea & & $1.30[1.19$ to 1.42$]$ & $1,174[572$ to 1776$]$ \\
\hline \multirow[t]{3}{*}{ Exacerbation history } & no exacerbation & ref. & ref. \\
\hline & mild exacerbation & $1.08[0.90$ to 1.29$]$ & $142[-1,126$ to $I, 4 \mid \mathrm{I}]$ \\
\hline & $\begin{array}{l}\text { moderate } \\
\text { exacerbation }\end{array}$ & $1.23[1.12$ to 1.35$]$ & 941 [299 to I583] \\
\hline
\end{tabular}


Table 6 (Continued).

\begin{tabular}{|c|c|c|c|}
\hline & & $\begin{array}{l}\text { Future costs (Table 3) - Gamma regres- } \\
\text { sion model }\end{array}$ & $\begin{array}{l}\text { Cost increases (Table 4) - Change } \\
\text { Score model }\end{array}$ \\
\hline & & Total Direct costs & Total Direct costs \\
\hline & $\begin{array}{l}\text { severe } \\
\text { exacerbation }\end{array}$ & $1.73[1.55$ to 1.93$]$ & I,53I [685 to 2377] \\
\hline Direct costs at baseline ${ }^{a}$ & & - & $-681[-740$ to -623$]$ \\
\hline Goodness of fit & Scaled Deviance & 1.1230 & 1.0154 \\
\hline
\end{tabular}

Notes: Estimates with $p<0.05$ are printed in bold. ${ }^{2}$ Direct costs at baseline per $€ \mathrm{I}, 000$. Inverse Probability Weights were calculated based on the probability of participating in the follow-up. Weights ranged between 1.07 and 2.52 and the sum of weights was 2408 , imitating the cohort at baseline.

The increase in healthcare utilization and direct costs over 18 months was accompanied by a small but statistically significant mean decline in lung function, and increases in the proportion of patients reporting dyspnea, underweight, and with a higher number of comorbidities. Over this period, the proportion of current smokers in our study population decreased. We also observed a decrease in the proportion of patients reporting a severe exacerbation within the previous 12 months. This might be due to the recruitment process of the baseline cohort. Although having had a severe exacerbation within the last four weeks was defined as an exclusion criterion of study participation, those who were admitted to the hospital had a higher change of being recruited into the study as soon as their disease status stabilized.

With our first set of regression models (Table 3), we amended the direct cost model published by Wacker et al, ${ }^{12}$ based on cross-sectional baseline data of the COSYCONET cohort. Cross-sectional analyses of cost determinants can be criticized, because cost estimates are usually based on healthcare utilization in the time period of up to 12 months before assessment and thus causality remains unclear. By using data collected at a follow-up visit, we were able to separate the assessment of baseline characteristics (possible predictors) and the self-reported healthcare utilization and related costs (future costs). In doing so, we could identify determinants of future direct costs, which were not included in the previous analyses ${ }^{12}$ as they would simultaneously count as patient characteristics and resource utilization; eg, severe exacerbations are, by definition, connected with a hospital stay and therefore contribute to inpatient costs. In the present analysis a history of moderate and severe exacerbations was not only associated with direct costs but also predicted future direct costs.

The results of the change score models shown in Table 4 further emphasize the role played by exacerbations, symptoms, and comorbidities, this time in predicting cost increases over a period of 18 months. The comorbidity count, as well as dyspnea and a history of exacerbations were associated with increased costs in outpatient and inpatient care, medication, rehabilitation, and physiotherapy as reported at the follow-up visit. Previous studies have already identified underweight as a risk factor for mortality and higher healthcare costs in COPD. ${ }^{28,29}$ In our study, underweight was not only a major predictor of future costs and increases in costs, but the effect estimates were similar to or even greater than those of GOLD grade 4, compared to grade 1. In accordance with the cross-sectional findings, higher COPD grades and higher age were important predictors of increasing costs.

Of additional interest are results concerning the unclassified GOLD grade participants, who had not been included in the baseline study, ${ }^{12}$ but clearly demonstrated high healthcare costs. Remarkably, all analyses showed effect estimates closer to those for GOLD grade 2 than GOLD grade 1. However, these remained non-significant. These findings underline that patients with physician diagnosed COPD with an unclassified GOLD grade do carry a significant disease burden and should be studied further.

When analyzing unadjusted costs, standardized to 2012 unit costs, only medication costs significantly increased between the two time points. However, there are different potential biases to these analyses. For one, although there were different recruitment paths for the COSYCONET study and ongoing exacerbations were an exclusion criterion, it can still be expected that patients had a higher likelihood to be recruited if they had received inpatient or outpatient health care within the last 12 months before baseline. In addition, participants still alive but lost to follow-up can be expected to be in worse health and therefore receiving increased health care in the follow-up period. The sensitivity analysis, which included IPW, indicated that the complete case analysis 
slightly underestimated the impact of various predictors on increases in direct costs at follow-up, but identified the same baseline variables as predictors of costs. However, the exclusion of patients lost to follow up from the longitudinal analysis may also have induced an underestimation of the overall mean change in costs over time. Nevertheless, this limitation is inevitable within prospective cohort studies of a broad spectrum of patients, some of whom can show deteriorations preventing them from participation in follow-up visits.

Besides non-participation bias, there are further limitations in this study, particularly the potential for recall bias in the self-reported healthcare utilization. While the follow-up period of 18 months may be considered a limitation, it is important to note that we were interested in revealing whether changes would occur even over a short period of time. As a further limitation, costs beyond inpatient and outpatient care, medication, rehabilitation and physiotherapy were not captured within this study, and thus 'real' total direct costs may be higher due to the exclusion of important healthcare-related costs, eg, for nursing care and medical devices such as oxygen therapy at home. Finally, due to the design of the questionnaire which was used to assess healthcare utilization, it was not possible to disentangle diseaserelated costs from overall healthcare costs. However, in practice this differentiation is very difficult, because COPD is recognized as a systemic disease with extrapulmonary manifestations.

Conversely, one of the strengths of our analyses is that in contrast to previously published longitudinal studies of costs based on administrative data in COPD, they are based on data from a prospective, multicenter cohort study that collected detailed, standardized clinical and demographics characteristics. ${ }^{13}$ This enables us to identify predictors of future costs and cost changes over time, favored by a large sample size.

In conclusion, through analysis of intra-individual changes in the utilization of healthcare services and the associated costs, we identified cost-drivers that were clinically plausible and relevant even within the short time period of 18 months. Taking costs as an overall indicator of health status, this may help in guiding therapy decisions based on those characteristics deemed to be most important for the course of the disease.

\section{Data Availability}

The full dataset supporting the conclusions of this article is available upon request and application from the
Competence Network Asthma and COPD (ASCONET, http://www.asconet.net/html/cosyconet/projects).

\section{Acknowledgments}

This work was supported by the Competence Network Asthma and COPD (ASCONET). The COSYCONET COPD Cohort is funded by the German Federal Ministry of Education and Research (BMBF) with grant numbers 01GI0881/01GI0882 and by unrestricted grants from AstraZeneca $\mathrm{GmbH}$, Boehringer Ingelheim Pharma $\mathrm{GmbH}$ \& Co. KG, GlaxoSmithKline, Grifols Deutschland GmbH, Novartis Deutschland GmbH. The funding body had no involvement in the design of the study, or the collection, analysis or interpretation of the data. The authors would like to thank all study centers which contributed in patient recruitment and data collection/capture: Andreas, Stefan (Fachklinik für Lungenerkrankungen, Immenhausen); Bals, Robert (Universität des Saarlandes); Kronsbein Juliane (Berufsgenossenschaftliches Universitätsklinikum Bergmannsheil, Bochum); Bewig Burkhardt (Universitätsklinikum Schleswig Holstein); Buhl Roland (Universitätsmedizin der Johannes-Gutenberg-Universität Mainz); Ewert Ralf (Universitätsmedizin Greifswald); Ficker Joachim (Klinikum Nürnberg Nord); Grohé Christian (Ev. Lungenklinik Berlin); Gogol Manfred (Krankenhaus Lindenbrunn); Hauck Rainer (Kliniken Südostbayern AG, Kreisklinik Bad Reichenhall); Herth Felix (Thoraxklinik Heidelberg gGmbH); Höffken Gerd Fachkrankenhaus Coswig GmbH), Huber Rudolf-Maria (Klinikum derUniversität München); Jany Berthold (Klinikum Würzburg Mitte, Standort Missioklinik), Katus Hugo A (Universitätsklinikum Heidelberg); Kenn Klaus (Schön Kliniken Berchtesgadener Land), Kropf-Sanchen Cornelia (Universitätsklinikum Ulm); Lange Christoph (Forschungszentrum Borstel), Magnussen Helgo (Pneumologisches Forschungsinstitut an der Lungenclinic Grosshansdorf GmbH); Pfeifer Michael (Klinik Donaustauf); Randerath Winfried J (Wissenschaftliches Institut Bethanien e. V., Solingen); Schumann Christian (Universitätsklinikum Ulm); Seeger Werner (Justus-Liebig-Universität Gießen); Studnicka Michael (Uniklinikum Salzburg), Taube Christian und Teschler Helmut (Ruhrlandklinik gGmbH Essen); Timmermann Hartmut (Hamburger Institut für Therapieforschung); Virchow J Christian (Universitätsklinikum Rostock); Vogelmeier Claus (PhilippsUniversität Marburg), Wagner Ulrich (Klinik Löwenstein gGmbH); Welte Tobias (Medizinische Hochschule 
Hannover); Wirtz Hubert (Universität Leipzig), Zabel Peter (Forschungszentrum Borstel); Ziegler-Heitbrock, Loems (Asklepios Klinik München-Gauting). Finally, they thank David Young of Young Medical Communications and Consulting Ltd for his critical review of the manuscript. This was funded by the German Federal Ministry of Education and Research (BMBF) Competence Network Asthma and COPD (ASCONET). The abstract of this paper was presented at the ERS International Congress 2018 as a poster presentation with interim findings. The poster's abstract was published in "Identifying predictors of healthcare utilization and costs in COPD patients over 18 months: first longitudinal results of the COSYCONET cohort" in European Respiratory Journal: DOI 10.1183/13993003.congress-2018.PA3152'.

\section{Disclosure}

Johanna I Lutter reports grants from German Federal Ministry of Education and Research during the conduct of the study. Stefan Karrasch reports grants from German Federal Ministry of Education and Research (BMBF) during the conduct of the study. Holger Schulz report grants from German Federal Ministry of Education and Research (BMBF), during the conduct of the study. Claus Vogelmeier report grants and personal fees from AstraZeneca, grants and personal fees from Boehringer Ingelheim, personal fees from CSL Behring, personal fees from Chiesi, grants and personal fees from GlaxoSmithKline, grants and personal fees from Grifols, personal fees from Menarini, personal fees from Mundipharma, grants and personal fees from Novartis, personal fees from Teva, personal fees from Cipla, grants from Bayer Schering Pharma AG, grants from MSD, and grants from Pfizer outside the submitted work. Rolf Holle report grants from German Federal Ministry of Education and Research, during the conduct of the study. The authors report no other conflicts of interest in this work.

\section{References}

1. Lozano R, Naghavi M, Foreman K, et al. Global and regional mortality from 235 causes of death for 20 age groups in 1990 and 2010: a systematic analysis for the Global Burden of Disease Study 2010. Lancet. 2012;380 (9859):2095-2128. doi:10.1016/S0140-6736(12)61728-0

2. Geldmacher H, Biller H, Herbst A, et al. [The prevalence of chronic obstructive pulmonary disease (COPD) in Germany. Results of the BOLD study]. Dtsch Med Wochenschr. 2008;133 (50):2609-2614.

3. Soriano JB, Abajobir AA, Abate KH, et al. Global, regional, and national deaths, prevalence, disability-adjusted life years, and years lived with disability for chronic obstructive pulmonary disease and asthma, 1990-2015: a systematic analysis for the Global Burden of Disease Study 2015. Lancet Respir Med. 2017;5(9):691-706. doi:10.1016/S2213-2600(17)30234-5
4. Mathers CD, Loncar D, Samet J. Projections of global mortality and burden of disease from 2002 to 2030. PLoS Med. 2006;3(11):e442. doi:10.1371/journal.pmed.0030442

5. Wacker ME, Hunger M, Karrasch S, et al. Health-related quality of life and chronic obstructive pulmonary disease in early stages longitudinal results from the population-based KORA cohort in a working age population. BMC Pulm Med. 2014;14:134. doi:10.1186/1471-2466-14-134

6. Wacker ME, Jorres RA, Karch A, et al. Assessing health-related quality of life in COPD: comparing generic and disease-specific instruments with focus on comorbidities. BMC Pulm Med. 2016;16 (1):70. doi:10.1186/s12890-016-0276-3

7. Foo J, Landis SH, Maskell J, et al. Continuing to confront COPD international patient survey: economic impact of COPD in 12 countries. PLoS One. 2016;11(4):e0152618. doi:10.1371/journal.pone.0152618

8. Blanchette CM, Gross NJ, Altman P. Rising costs of COPD and the potential for maintenance therapy to slow the trend. Am Health Drug Benefits. 2014;7(2):98-106.

9. Global Initiative for Chronic Obstructive Lung Disease. Global Strategy for the Diagnosis, Management, and Prevention of Chronic Obstructive Pulmonary Disease 2017 Report; 2017. Available from http://www.goldcopd.org/. Accessed June 18, 2019.

10. van der Schans S, Goossens LM, Boland MR, et al. Systematic Review and Quality Appraisal of Cost-Effectiveness Analyses of Pharmacologic Maintenance Treatment for Chronic Obstructive Pulmonary Disease: methodological Considerations and Recommendations. PharmacoEconomics. 2017;35(1):43-63. doi: 10.1007/s40273-016-0448-2

11. Fletcher MJ, Upton J, Taylor-Fishwick J, et al. COPD uncovered: an international survey on the impact of chronic obstructive pulmonary disease [COPD] on a working age population. BMC Public Health. 2011;11:612. doi:10.1186/1471-2458-11-612

12. Wacker ME, Jorres RA, Schulz H, et al. Direct and indirect costs of COPD and its comorbidities: results from the German COSYCONET study. Respir Med. 2016;111:39-46. doi:10.1016/j. rmed.2015.12.001

13. Karch A, Vogelmeier C, Welte T, et al. The German COPD cohort COSYCONET: aims, methods and descriptive analysis of the study population at baseline. Respir Med. 2016;114:27-37. doi:10.1016/j. rmed.2016.03.008

14. Icks A, Dittrich A, Brune M, et al. Agreement found between self-reported and health insurance data on physician visits comparing different recall lengths. $J$ Clin Epidemiol. 2017;82:167-172. doi:10.1016/j.jclinepi.2016.10.009

15. WHO Collaborating Centre for Drug Statistics Methodology. Guidelines for ATC Classification and DD Assignment 2010. Oslo: WHOCC; 2009.

16. Bock JO, Brettschneider C, Seidl H, et al. [Calculation of standardised unit costs from a societal perspective for health economic evaluation]. Gesundheitswesen. 2015;77(1):53-61.

17. Research Institute of the AOK. 2017. Available from: http://wido.de/ forschung-projekte/arzneimittel/. Accessed June 18, 2019.

18. Jones PW, Quirk FH, Baveystock CM, Littlejohns P; The St. George's Respiratory Questionnaire. A self-complete measure of health status for chronic airflow limitation. Am Rev Respir Dis. 1992;145(6):1321-1327. doi:10.1186/s12890-016-0276-3

19. Quanjer PH, Stanojevic S, Cole TJ, et al. Multi-ethnic reference values for spirometry for the 3-95-yr age range: the global lung function 2012 equations. Eur Respir J. 2012;40(6):1324-1343. doi:10.1183/09031936.00213711

20. Karl FM, Holle R, Bals R, et al. Costs and health-related quality of life in Alpha-1-Antitrypsin Deficient COPD patients. Respir Res. 2017;18(1):60. doi:10.1186/s12931-017-0543-8

21. Jones PW, Brusselle G, Dal Negro RW, et al. Properties of the COPD assessment test in a cross-sectional European study. Eur Respir J. 2011;38(1):29-35. doi:10.1183/09031936.00177210 
22. Fletcher CM, Clifton M, Fairbairn AS, et al. Standardised questionnaire on repsiratory symptoms: a statement prepared and approved by the MRC Committee on the Aetiology of Chronic Bronchitis (MRC breathlessness score). BMJ. 1960;(2):1662.

23. Putcha N, Puhan MA, Drummond MB, et al. A simplified score to quantify comorbidity in COPD. PLoS One. 2014;9(12):e114438. doi:10.1371/journal.pone.0114438

24. Wacker ME, Kitzing K, Jörres RA, et al. The contribution of symptoms and comorbidities to the economic impact of COPD: an analysis of the German COSYCONET cohort. Int J Chron Obstruct Pulmon Dis. 2017;12:3437. doi:10.2147/COPD.S150887

25. Jansson SA, Backman H, Stenling A, Lindberg A, Ronmark E, Lundback B. Health economic costs of COPD in Sweden by disease severity-has it changed during a ten years period? Respir Med. 2013;107(12):1931-1938. doi:10.1016/j.rmed.2013.07.012
26. Menn P, Heinrich J, Huber RM, et al. Direct medical costs of COPD-an excess cost approach based on two population-based studies. Respir Med. 2012;106(4):540-548. doi:10.1016/j.rmed. 2011.10.013

27. Lee J, Lee JH, Kim JA, Rhee CK. Trend of cost and utilization of COPD medication in Korea. Int J Chron Obstruct Pulmon Dis. 2017;12:27-33. doi:10.2147/COPD.S150887

28. Landbo C, Prescott E, Lange P, Vestbo J, Almdal TP. Prognostic value of nutritional status in chronic obstructive pulmonary disease. Am J Respir Crit Care Med. 1999;160(6):1856-1861. doi:10.1164/ ajrccm.160.6.9902115

29. Jo YS, Kim YH, Lee JY, et al. Impact of BMI on exacerbation and medical care expenses in subjects with mild to moderate airflow obstruction. Int J Chron Obstruct Pulmon Dis. 2018;13:2261-2269. doi:10.2147/COPD.S163000

\section{Publish your work in this journal}

The International Journal of COPD is an international, peer-reviewed journal of therapeutics and pharmacology focusing on concise rapid reporting of clinical studies and reviews in COPD. Special focus is given to the pathophysiological processes underlying the disease, intervention programs, patient focused education, and self management protocols. This journal is indexed on PubMed Central, MedLine and CAS. The manuscript management system is completely online and includes a very quick and fair peer-review system, which is all easy to use. Visit http://www.dovepress.com/testimonials.php to read real quotes from published authors. 